\title{
A "separation of worlds": The support and social networks of family carers of people with dementia at the end of life, and the possible role of the internet
}

Nathan Davies*

Centre for Ageing Population Studies, Research Department of Primary Care and Population Health, University College London, Rowland Hill Street, London, NW3 2PF, UK

Centre for Dementia Palliative Care Research, Marie Curie Palliative Care Research Department, University College London, Tottenham Court Road, London, W1T 7NF n.m.davies@ucl.ac.uk

Nina Walker

Centre for Ageing Population Studies, Research Department of Primary Care and Population Health, University College London, Rowland Hill Street, London, NW3 2PF, UK

n.walker@ucl.ac.uk

Jenny Hopwood

Centre for Ageing Population Studies, Research Department of Primary Care and Population Health, University College London, Rowland Hill Street, London, NW3 2PF, UK

\section{jenny.hopwood@cantab.net}

Steve lliffe

Centre for Ageing Population Studies, Research Department of Primary Care and Population Health, University College London, Rowland Hill Street, London, NW3 2PF, UK

s.iliffe@ucl.ac.uk

Greta Rait

Centre for Ageing Population Studies, Research Department of Primary Care and Population Health, University College London, Rowland Hill Street, London, NW3 2PF, UK

Priment Clinical Trials Unit, Research Department of Primary Care and Population Health, University College London, Rowland Hill Street, London, NW3 2PF, UK g.rait@ucl.ac.uk

Kate Walters

Centre for Ageing Population Studies, Research Department of Primary Care and Population Health, University College London, Rowland Hill Street, London, NW3 2PF, UK k.walters@ucl.ac.uk 
*corresponding author 


\section{ABSTRACT}

Caring for someone with dementia is one of the most challenging caring roles; however, the demands of the role towards the end of life often means carers are unable to maintain faceto-face support. The aim of this study was to: 1) Explore the experiences of older (over 65 years) family carers of people with dementia of support towards the end of life; 2) Explore with family carers the role of the internet as a support for them at the end of life. Semistructured interviews were conducted, with purposive sampling from general practice and research networks to recruit 20 current and former family carers aged 65 and over in England (2016-2017). Interviews were audio-recorded, transcribed and analysed using thematic analysis. An over-arching theme of the 'separation of worlds' (the internal caring world and the outside world of society) was identified, with four sub themes: 1) the support role of relationships and social networks; 2) loss as a consequence of caring; 3) reconstruction of life as a carer; and finally; 4) life within and beyond the computer screen. This study demonstrates the complexity of social support at the end of life for family carers depicted in a model of two worlds. The internet can be seen as a viable approach to help carers maintain existing networks, reconstruct networks they have lost or developing new networks to meet their new needs and circumstances as a carer. Future support interventions should focus on a mixed model of technology and human interaction.

\section{KEYWORDS}

Dementia, caregiver, end of life care, palliative care, social networks, loneliness, relationships, older people, qualitative research

\section{What is known about this topic?}

- Caring for someone with dementia is one of the most challenging caring roles

- Family carers report a lack of support towards the end of life 


\section{What this paper adds}

- Carers report a separation of their caring world from the outside world of society

- Carers feel a series of losses through their social networks however attempt to reconstruct these networks to meet their new needs and circumstances

- The internet can provide support including options to develop new relationships and networks, however the internet alone is not enough and human interaction is still needed

\section{BACKGROUND}

There are currently around 700,000 family members and friends acting as primary carers (i.e. provide the majority of care) of people with dementia in the UK (Lewis, Karlsberg Schaffer, Sussex, O'Neill, \& Cockcroft, 2014). For the purpose of this paper we will refer to family and friends as 'carers', their family members who do not act as a carer to their relative with dementia as 'family members'. Without the help of such carers the formal care system would be likely to collapse (Alzheimer's Society, 2013).

Caring for someone with dementia is thought to be one of the most challenging caring roles (Kneebone \& Martin, 2003) with implications for both the physical and psychological health of the carer. Studies have reported higher levels of depression, emotional distress, and physical strain in carers of people with dementia compared to carers for older adults with physical impairments (Cuijpers, 2005; Ory, Hoffman, Yee, Tennstedt, \& Schulz, 1999).

Many carers report a lack of support with the difficulties of caring for someone with dementia, and this can be heightened towards the end of life (Davies, Maio, Rait, \& lliffe, 2014; Davies, Rait, Maio, \& lliffe, 2017).The end of life can create many complexities and challenges for carers. Many will be supported through this period by friends, family and professionals. However, for some this will be a period in their life where social and support 
networks are already depleted due to ageing, poor health and bereavements. There has been an increase in both academic research (Kharicha, Manthorpe, lliffe, Davies, \& Walters, 2018) and media attention to loneliness and social networks worldwide. The consequences of caring on social relationships and networks requires further exploration (Keating \& Eales, 2017).

Family carers of someone with dementia may be particularly at risk of disruption of social networks with high levels of burden, stress and time spent caring. Previous work has reported that carers of people with dementia feel socially isolated (Davis, Gilliss, DeshefyLonghi, Chestnutt, \& Molloy, 2011), with reduced social networks (Cheng, Lam, Kwok, Ng, \& Fung, 2013) but also can find new ways to remain socially engaged (Nay, Bauer, Fetherstonhaugh, Moyle, Tarzia, \& McAuliffe, 2015).

Social networks have been described in the dementia care literature as an important means to counter isolation and identify positive experiences in caring (Duggleby, Williams, Wright, \& Bollinger, 2009; O'Connor, 2007). It is therefore important to explore support for carers of people with dementia, particularly when the person with dementia is approaching the end of life. There has been a limited focus on carers experiences of end of life (Davies, Maio, Rait, \& lliffe, 2014; Broady, Saich, \& Hinton, 2018), and to date only a few studies have specifically explored the social and support networks of family carers of people with dementia qualitatively (Daly, McCarron, Higgins, \& McCallion, 2013; Dam, Boots, van Boxtel, Verhey, \& de Vugt, 2017) and we are not aware of any studies exploring social and support networks at the end of life.

It is also important to understand how carers receive support, especially at the end of life when sources of help and carers' time may be limited. The internet may be a tool to bridge a support gap and meet the needs of those who provide care for someone with dementia at home and find it difficult to access support. Some have demonstrated a capacity for internet 
based interventions to improve aspects of carer well-being including reduced depression, burden and stress (Hopwood, Rait, Walters, Iliffe, Ross, \& Davies, 2018), or even a role in reducing social isolation (Heo, Chun, Lee, Lee, \& Kim, 2015).

Statistics demonstrate that the use of the internet is increasing in older adults (over 65 years) (Office for national Statistics, 2017; Zickuhr K \& Madden M, 2012). The use of websites and online resources for health and care-based information has been steadily increasing, for example in the UK NHS Choices (www.nhs.uk) and specifically for dementia the Alzheimer's Society website (www.alzheimers.org.uk). A recent review found there were a series of resources to support carers of people with dementia; however, none of these resources focussed on end of life (Hopwood, Rait, Walters, lliffe, Ross, \& Davies, 2018). Little work has explored how the internet may be useful for meeting the specific challenges that older family carers of people with dementia face.

\section{Aim}

The aim of this study was to: 1) Explore the experiences of older (over 65 years) family carers of people with dementia of support towards the end of life; 2) Explore with older family carers the role of the internet as a support for them at the end of life.

\section{METHODS}

\section{Design}

Qualitative methods using semi-structured interviews and analysed using thematic analysis (Braun \& Clarke, 2006). This study was an explorative qualitative study guided by a constructivist theoretical stance, which ensured an inductive approach to data collection and analysis.

\section{Participants and recruitment}


Family carers (current and former) were recruited through third sector organisations in England, including two local carer charities in North London and Hertfordshire, local offices of Age UK in London, and the Alzheimer's Society. This was supplemented with recruitment from Join Dementia Research (JDR) and from interested general practices within London and Essex. General practices were identified by Clinical Research Networks (CRN) who have a portfolio of local research active practices. The CRN emailed a list of practices with a short description of the study and activities which would be required by them. If interested practices returned an expression of interest form and were contacted by the research team to receive more information and organise recruitment of participants via the practices.

Older family carers (65 years and above) were purposively sampled for internet usage (no or minimal use of the internet, moderate use of the internet (e.g. weekly) and high use of the internet (e.g. daily)) in addition to monitoring for gender, ethnicity/language and education to ensure maximum diversity of the sample. Recruitment continued until no new themes were being generated from the data (data saturation) (Glaser \& Strauss, 1967).

\section{Inclusion criteria}

- Carers currently caring or experience as a former carer (within last three years) for someone with dementia at the end of life

- Carers 65 years of age and older

\section{Exclusion criteria}

- Carers bereaved within the last 3 months

- Carers unable to speak English

Due to the difficulties of prognosis and defining end of life in dementia (Brown, Sampson, Jones, Barron, 2013), for this study end of life was defined by the family carers participating. Participants were asked to decide whether their relative was at the end of life and if they felt 
they were at the end of life they were eligible to participate, following approaches in similar studies (Davies, Rait, Maio, \& lliffe, 2017).

\section{Procedure}

Invitations were sent to eligible participants by general practices and third sector organisations, by post or email, providing information on the study and inviting expressions of interest. Interested participants were followed up by the research team by telephone to provide further information and arrange an interview.

Interviews were conducted face-to-face in the carer's home because of the sensitive nature of the topic, by experienced researchers (two psychologists (authors initials blinded for review) and one general practitioner (authors initials blinded for review), experienced in qualitative research) in 2016-2017. Interviews were audio recorded and transcribed verbatim for analysis.

Analysis: Data analysis began through familiarisation of transcripts and initial coding on the completion of the first interview to inform data collection in subsequent interviews. Interviews were analysed using thematic analysis methods (Braun \& Clarke, 2006), using an inductive approach to coding. Transcripts were read by two authors (authors' initials blinded for review) and a selection of transcripts by a third author (authors' initials blinded for review) to familiarise themselves with the data. Two researchers independently coded the interviews and met to discuss their coding and agree a coding frame. Following this one researcher coded all the interviews with the agreed coding framework on paper using highlighting and written annotations, and developed the themes further searching for negative and deviant cases to increase the rigour (Mays \& Pope, 2000). Discussions with other members of the team (authors' initials blinded for review) and an external advisor in medical sociology developed the model in Fig. 1 and revised the themes further. The iterative and multidisciplinary team approach to the analysis increased the rigour (Mays \& Pope, 2000). 


\section{Ethics}

Ethical permission was approved by a National Health Service (NHS) Ethics Committee (Ref blinded for review). University ethical approval was provided for participants recruited outside of the NHS (Ref blinded for review). All participants provided informed written consent to participate.

\section{FINDINGS}

Twenty family carers; including 16 individuals and two couples, were interviewed (see table 1). The interviews highlighted not only the importance but also the complexity of relationships, support and social networks for individuals providing care for someone with dementia towards the end of life. .

Table 1. Near here

\section{SEPARATION OF WORLDS}

There was an overarching theme of separation, particularly the separation of two worlds.

Carers described an experience of living as a carer within a segregated 'world' of caring and dementia. This internal world appeared separate from an external, outside world of society. Participants balanced living within the internal world with maintaining a status and function in the outside world.

Separation of worlds was constructed by three themes: 1) The support role of relationships and social networks; 2) loss as a consequence of caring; and 3) reconstruction of life as a carer. Loss and reconstruction were closely related to a final fourth theme of how the internet may provide support: life within and beyond the computer screen. 
"The life of a carer was a lonely one. Very insular. We lost all of our friends, because mum wouldn't allow me to be with anybody other than her. She got jealous of my son and my grandchildren. She wouldn't even let the grandchildren come here." (B005, Daughter)

"[...] the general public feel very sorry for us. They don't like dementia, because they don't know how to deal with it. It's got a stigma, it's something which excludes you." (C013, Wife)

\section{The support role of relationships and social networks}

Support from networks, including other family carers (peers who also care for their own relative with dementia), friends, family members and professionals was integral to participants' caring role. They often talked about a belonging to other family carers as part of a group, and discussed an absence of their own family members and friends. Carers discussed their relationships with health and social care professionals, which appeared to be either some limited relationship or no relationship at all.

Each relationship and network had a function and provided different sources of support including instrumental (practical), emotional and informational. These relationships were dispersed across an internal world of caring and an outside world of society. We return to this in the Discussion.

Participants particularly highlighted a contrast between the support which was provided by friends compared to other family carers in the 'same boat' as them. The support with existing friends often did not involve discussions around caring; however with other family carers it often included honest and open discussions about caring, acting as a source of emotional support and strength: 
"It was very, very good [carer support group]. It wasn't sort of a pity-fest although we did kind of talk to each other. We did actually give each other [other family carer] a bit of ideas and strength and stuff." (B007, Wife)

Existing friends did not always quite understand their situation or their place in an 'internal world' and therefore could not provide this support:

"My friend whose mum died when she was 72 of cancer and was well until the last few weeks said the other day "does your mother-in-law still go to parties?" I said she's in a home, she's 107. "yes but does she still go to parties" (laughing)" (C017, Daughter/ Daughter-in-law)

Other family carers also offered practical and informational support about end-of-life care, providing a more comprehensive form of support than family members and friends, for example advice around incontinence:

"[...] incontinence advice or where to find, to, you know, where to get the information really, because that is a big issue, particularly once they're in bed and you're turning them, and using slide sheets" (C014)

For some the background of the individual providing support was not important. However, for many they did not want support from other family carers (emotional or informational). For them their own problems were enough, they did not want to hear other people's problems:

"I never seemed to be able to find anyone [other family carers] who was [experiencing the same]- or they sounded so depressed and so, you know... We'd just sit there and talk death. "oh l'm depressed." "So am I" ". (B019, Daughter) 
For these groups of participants they were able to find support and comfort in their existing friends and families:

"I am very lucky that I got my sister, because we chat" (C017, Daughter/ Daughter-inlaw)

Professionals were often seen by most people as knowledgeable and a source of trusted authority for informational and instrumental support but for some participants they felt they lacked emotional rapport:

"Professionals are not always, how can I put it. Because they haven't got the first-hand experience. [...] They wouldn't have any empathy." (B002 Wife)

Overall participants described an emphasis of comprehensive support provided by other family carers. However, some preferred support from their own family members and friends, but not necessarily related to issues around caring.

\section{Loss as a consequence of caring}

Family carers portrayed a journey of loss which in some cases was represented as exclusion, isolation and possible loneliness. It was described not only more by spouses compared to adult children, but also more intensely. Loss was felt across their lives from family members, friends and companionship, through to a loss of their own lives including their past and future.

Loss of family, friends and withdrawal from society

As dementia progressed there was a loss of both friends and family members. As the quote below illustrates carers perceived that the lack of understanding by some friends meant that 
their friends no longer wanted to socialise with the person with dementia and themselves the carer:

"I had some close friends, [...]. we'd been out for a meal, as we came into the house [...] the wife and myself were on our own, she says, I don't know how to cope with Angela's [person with dementia -pseudonym] repetition. I regret to this day that I didn't go back quickly and say, the same way as we've coped with Dave's depression all these years. Anyway, I mean in the end they just, we were going out socially to a dinner, and they cancelled. [...] Anyway, I did a little note to them saying it's obvious you don't want to socialise with us, let's not play games, you can have you keys back and I'll have mine back. " (B004, Husband)

A loss of support was particularly notable in accounts of the withdrawal of their own family members. Adult children experienced the emotional withdrawal of siblings who no longer wanted to be involved in the care of their parent. This created an element of separation between the family carer and their family. It was particularly complicated at the end of life as difficult decisions needed to be made and support from relatives was wanted:

"I have a sister who lives about fifteen miles away from my mum. But she, for whatever reason, just wasn't really interested in helping my mum. She would see her socially maybe for going out, doing her shopping at the same time my mum did her shopping, on a Friday, maybe have lunch or something that my mum would pay for. And then they would go home." (C015, Son)

Some described this as a systemic loss across all networks including society as a whole, creating separation and a split between them as a carer and the rest of society: 
'When this happens, when they use the word 'devastating', it is absolutely devastating on many, many levels - the families withdraw, the old friends withdraw, the society withdraws." (C013, Wife)

Loss and changes in companionship

There was a parallel in the interviews of the loss of friends, family members and society matching the loss of the emotional relationship they had with the person they were caring for. For some this was a loss of companionship with their spouse, but for some adult children a loss of the relationship they had with their parent was replaced with a new kind of relationship and emotional bond. This was exacerbated at the end of life when there was a lack of communication, with the individual:

"The last six months he barely opened his eyes, he just shut off from the world and stopped speaking, rarely opened his eyes.” (B019, Daughter)

\section{Loss of themselves and their life, present and future}

Finally, carers also felt a loss of themselves. There was a feeling that they had left behind another life and were retreating into a world of just being a carer. For many this former life encompassed a strong social aspect with multiple networks of friends or acquaintances; for example for one carer it was represented by a wardrobe full of clothes no longer worn, reflecting their former lost life:

"We don't buy many clothes. I've got a wardrobe full of them. The life I led. I was on the mental health review tribunal and now, you've got to dress reasonably smartly if you go off [to] these psychiatric institutions and be serious. When I was at the [teaching hospital] and [local district general hospital] and doing various things and also going out in the evening. I've got all these clothes that I never wear any more. It's jeans and more jeans." (CO03, Wife) 
Carers felt a loss for their future, including for many a loss of their plans for retirement. Many could see that this was not the end of their own future life and retirement, but it was the loss of their shared retirement with their spouse and the life they had planned for together:

"My birthday was a few days ago and I am just 67 and our retirement was completely ruined." (B007, Wife)

\section{Reconstruction of life as a carer}

In contrast and response to the idea of loss, many participants appeared to describe the experience of reconstructing life as a family carer, including negotiating new social networks and connections. Family carers spoke positively of their reconstruction of social networks with other family carers who had similar experiences to themselves. This was needed at the end of life when discussions about caring could not be had with friends.

Carers discussed two reasons for building new networks. Firstly, to have freedom and have someone they are able to trust to be open with who, have a shared understanding and who could be part of their internal world:

"You can say exactly what you think [to other carers] like I wish my mother-in-law would die. [...] So you have guilt about thinking like that. You can actually say that to friends that you trust and who have got the same problems." (C017, Daughter/Daughter-inlaw)

Secondly, it gave them a place back in the outside world and allowed them an opportunity to escape their internal caring world and enter the outside world once again, giving them a sense of belonging: 
"Carer: Although when I have a problem [with caring] I am completely obsessed by the problem, I am not really terribly interested in, like dementia. But once I read several books about it I just wanted to move on. I don't want to stay in this dementia thing because it fills up so much of our life anyway.

Interviewer: links back to what you said about the group being more of a distraction than.

Carer: Yes, something to take you out of yourself." (C017, Daughter/Daughter-inlaw)

In reconstructing social networks it broke down the separation between the family carers' caring world, and that of their life outside in society with social networks. The two reasons suggest other family carers can enter the internal world but also be part of the external world, therefore illustrating the blurring of boundaries.

\section{Life within and beyond the computer screen}

Views of the use of the internet to support family carers in their role tended to focus on provision of information or online support from others. For some the internet was a way of bringing life into the home with one participant describing the internet as being alive and potentially preventing further loss:

The internet - it is not alive, but it's alive in those of us that use it a lot, in a sense." (C013, Wife)

Some saw the internet as a platform to meet other people and offer a source of emotional or simply informational support, and a means of reconstructing networks:

"The only thing l've found on the web that was useful to me [...] it's a monthly, from all the queries that they've [national charity] had they put on this web site [chat forum] 
the problems people have raised and folk like myself can feed in how we've coped with it. Now I found that very good" (B004, Husband)

"I was trying at one stage to try and think if I could get a group of people actually in [the local area] that look after their spouses or mothers or fathers - but it didn't really work. I put it on Streetlife [website]." (C003, Wife)

However, it was described as a means of identifying people online, for example other family carers who understood their situation as discussed previously reconstructing their networks or obtaining information and not necessarily continued engagement or development of friendship online:

“Interviewer: And from that group [online social group] were you hoping to talk online or that you would meet?

Carer: Meet for coffee. Go for a walk. Telephone" (C003, Wife)

Other family carers online may also be considered as not real 'friends', suggesting a distinction between those met online and those in person:

"I have an enormous group of friends, I mean, you know, not Facebook friends, proper friends." (C013, Wife)

The potential of the internet for caring situations was also noted, for example some considered the use of Face Time and other communication software to keep in touch with people they were caring for remotely or other family members and also professionals, such as GPs to provide the information and support: 
"That might be a very good thing is, Face Time on the internet rather than anything else, because you are talking to them and he [doctor] can read body language as well at the same time. [...] You can actually show the patient to the doctor" (C010)

However, even those who described themselves as using the internet, struggled with the concept of the internet for engaging with others:

"It's just so impersonal" (B009, Daughter)

Two participants who did not use the internet simply had no interest in learning how to use it. Participants reported that their relatives used it for essentials on their behalf, and social networks were active and good with no need to 'reconstruct' or form new social networks:

"If I need help my son would turn up. [...] He lives [locally]. I've got very good neighbours to my left. " (C011, Wife)

There was a perception that many older people are 'scared' of the internet, because the language may be intimidating rather than its actual use being problematic:

"It's language, what people are used to and not frightened of or scared of and that's why I think maybe the word internet puts a lot of, elderly people, mature people off, because it sounds such a vague and technological masterpiece, but mobile phones they understand, nowadays" (C010, Son-in-law)

However many did use Facebook mainly to keep in touch with other people:

"I have now got friends on Facebook, so basically it is just for friends." (C017, Daughter/Daughter-in-law) 


\section{DISCUSSION}

The study explored support and social networks of family carers of people with dementia towards the end of life and the role of the internet in supporting them. The carers described a separation of two worlds; their internal caring world and the outside world of society with varying networks of support. Carers discussed a spectrum of losses but also a process of reconstruction of life as a carer. Finally, carers discussed the potential role of the internet in creating or maintaining supportive social networks. These findings build on a growing body of evidence on social networks in the caregiving literature (Keating \& Eales, 2017), including dementia, and is the first to our knowledge exploring social networks in end-of-life care in dementia.

\section{Separation of worlds}

As represented in Fig. 1 the interviews with participants indicated an overarching message of two separate worlds: the 'internal world', within which carers live most of their time; and the 'outside world' of wider society. The support and understanding of the caring situation that different networks provided, together with the loss experienced by carers, appears to create this separation of worlds through a construction of symbolic boundaries, (Lamont \& Molnár, 2002). This separation encourages carers to reconstruct their social networks, as seen in the findings.

Dispersed across the two worlds are the series of different networks carers describe: their own family members, friends, other family carers, practitioners, in addition to themselves (the carer) and the person with dementia. In Fig. 1 these networks are represented in circles with the degree to which the circle overlaps between the internal and outside worlds reflecting time spent by these networks in the two worlds. However, findings do not suggest that these two worlds are impermeable and networks may cross the boundary between the two worlds. 
Other family carers appear to cross the boundary and be more situated in the internal world than family members and friends do for many, reflecting a blurring of boundaries between the internal and the external worlds. This may be explained by the carers' suggestion that other non-carers did not understand their situation and were at times unable to be supportive in a way that fitted their 'new life' and marginalising them as carers (Keating \& Eales, 2017). They therefore often sought the support from other carers in the 'same boat' as them and understood how it was to feel marginalised and within an internal world. Other family carers in addition to being part of the internal world, also have a role and place in the external world and may therefore also act as a gateway to the external world for carers to escape. Practitioners cross this boundary less, reflected through carers descriptions of practitioners ability to only offer informational and some instrumental support.

Crossing of boundaries may occur in two ways. Firstly, family carers can control the crossing of others - for example new professionals or services - into their internal caring world. It has been argued by some that dominant groups create a dichotomy (outside and internal) in order to marginalize other groups and to some extent develop an element of control through blocking access to resources (Tilly, 1998). This could be a way of family carers regaining control over a situation, at a point when many feel a lack of control. Secondly, carers themselves could cross the boundary and move into the outside world and once more become integrated in a wider society. This separation of worlds and boundary crossing resonates with Keating and colleagues, who proposed two reasons of carers becoming isolated: social exclusion resulting from others staying away; and social isolation resulting from keeping others away (Keating \& Eales, 2017). A recent review from Broady and colleagues found that carers often report feeling lonely and socially isolated from family and friends (Broady, Saich, \& Hinton, 2018). The current findings suggest that carers and people with dementia feel stigmatised by other members of society and they seek the support of 
other family carers who know how it feels to be stigmatised, aligning with idea of social exclusion from Keating and Eales.

The loss and reconstruction of networks could suggest carers experience a series of transitions and find themselves negotiating social networks and connections. This supports previous work with carers of people with dementia. Lewis described carers' feelings of being entrapped by their role and overcoming this through a process of rediscovery. Lewis posed a five stage process whereby carers 1) miss their past, 2) sacrifice self, 3) yearn to escape, 4) reclaim their identity and 5) find joy (Lewis, 2015). Our model of separation (Fig. 1) reflects stages $1-3$ and the findings suggest that carers reclaim their identity through developing their social networks to fit their new role, their responsibilities and reality, reflecting stages four and five. Loss appeared to be discussed more often and more powerfully by spouses than adult children. This may reflect the shared lives spouses have, compared to adult children who have their own life and possibly spouse and children.

Similarly to Lewis, Daly and colleagues proposed a model of social processes employed by informal carers of people with dementia to cope with their changing social world (Daly, McCarron, Higgins, \& McCallion, 2013). They describe four interconnecting components which a carer transcends through in a dynamic manner as the dementia progresses: 'unsettled place'; 'threatened place'; 'sustaining our place'; and 'sustained place', with place representing the identity of the carer. They suggest that 'threatened place' and 'sustaining our place' occur later in the course of dementia, and this is supported by the findings of the current study which reflect these two phases. Carers experience disruption to belonging, purpose and direction, realising the disconnect from their pre-dementia lives ('threatened place'). This is evident in our study in the description of clothes they no longer wear and the loss of friends and social networks. Daly describes this point as increasingly restricted, a point where disruption pervades social lives and aspects of the life world are thrown into disarray. As seen in the current findings this a point when carers question their worth and 
value in society and seek to maintain this value and position. Daly describes this as 'sustaining our place'. At this point carers take action to maintain or fight to 'sustain place', including protective and defensive actions. In our findings this is evident through joining of informal networks such as carer groups, or searching for others online, representing a crossing of the boundary from the internal world of caring into the outside world of society. Finally, in Daley et al's. model carers reach 'sustained place'; however, this is dynamic and carers may return to 'threatened place' at any point if their social connectivity is jeopardised.

One interpretation of the current findings in relation to Daly and colleague's model is the idea of a separation of worlds should not be considered unique to end of life, but rather a continuous change to the social world of both the carer and person with dementia as the condition progresses.

\section{Role of the internet}

It is possible that the internet has a role in allowing boundaries to be crossed and new networks constructed. The internet could be seen as a boundary object. Boundary objects are artefacts that link diverse interests and allow groups to coalesce and form stable, if transitory, working relationships. Boundary objects encourage an individual's local understanding to be reframed in the context of a wider collective activity (Kimble, Greniera \& Goglio-Pinard 2010). In this study the internet linked carers to the internal caring world and the external world of society, but in different ways. Carers discussed meeting other carers online with whom they could engage and share a sense of support. In the near future it is likely the internet will play a larger role in the development and reconstruction of social networks for carers, as the current internet savvy population age and become carers themselves later in life. These online connections or groups, as reflected in this study, are linked through common identities but not necessarily direct face-to-face contact. This raises a question to whether these online communities are 'friends'? It has been argued that online connections or friends are "unreal friends" and are of less value than the "real thing" 
(Cocking \& Kennett, 1998). This was highlighted by participants in this study. However, Briggle argues that if used conscientiously the internet can support close friendships (Briggle, 2008).

There was no difference in views of spouses and adult children on the value of the internet, however the two participants who did not use the internet were spouses. Further work in the field should explore any differences.

\section{Implications for research, clinical practice and policy}

This study adds to the evidence base for informing future interventions to support carers of people with dementia (Daly, McCarron, Higgins, \& McCallion, 2013; Hopwood, Rait, Walters, Iliffe, Ross, \& Davies, 2018; Keating \& Eales, 2017; Lewis, 2015). The findings of this study suggest that there may be greater benefits from interventions aimed at increasing support from other carers rather than from professionals.

This study shows the potential of the internet to help support family carers of people with dementia. It suggests that 'friends' or supportive allies can be formed online as an additional source of informational, instrumental, and emotional support. However, the findings suggest future interventions which are aimed at providing support should be a mixed model of technology with an element of human interaction. For some the internet was a platform for identifying other carers with whom they could then meet locally, face-to-face.

The discussion of peer support is present throughout the interviews, however many did not want to hear about other carers problems as their own were enough. To counter this a 'buddy system' similar to that used in cancer services where cancer patients are paired with survivors, may have merit (Griffith, McGuire, \& Russo, 2010). Examples of which can be seen by a variety of charities including the testicular charity, It's On the Ball 
(Itsontheball.org). Carers towards the end of life could be 'buddied' with bereaved family carers, those who have been in the same situation.

The discussion of boundaries and two worlds in caring for someone with dementia is a debate which should be explored further. In particular how boundaries are imposed, either by: society and the stigma it holds of dementia; the carers perception of stigma; or a carers mechanism of creating and maintaining control. Further study of the internet as a boundary object could be fruitful.

\section{Strengths and limitations}

The sample was diverse in age and strengthened by recruiting participants with a variety of educational levels, however ethnic diversity was limited as the majority of participants were white British and the findings may not represent the views of those in black and minority ethic groups. Despite attempts to recruit family carers who did not use the internet, only two participants were recruited who did not use it. Despite this, not all participants used the internet on a daily basis and many reported they only used the internet for emails. A larger spread of internet usage among participants would have given a richer understanding of how the internet could be helpful or not to this population, in particular highlighting why some may not be keen on using the internet. All participants in this study lived in areas with good internet access, however further sampling of those who live in more rural areas where internet access is limited would expand the diversity in the sample and possible views and value of using the internet. Participants self-identified that the person that they were caring for was at the end of life. This is a difficult area to be precise about, which some variation in interpretation (Davies, Maio, Rait, \& lliffe, 2014; Davies, Rait, Maio, \& lliffe, 2017), however it was clear from interviews that for all participants they were either bereaved or the person they cared for was in the later stages of dementia.

\section{Conclusion}


This study has uniquely described an image of two worlds which interact; the internal world of caring and the outside world of society. This study demonstrates that relationships and networks are complex at the end of life. The internet is a viable approach to provide support for some carers, however an element of human interaction is needed.

\section{Acknowledgment}

The authors would like to thank (name anonymised for review) for her contribution to the model. They would also like to thank the funders and all family carers who participated in the research.

\section{Conflict of interest}

We have no conflict of interest have been declared.

\section{Funding}

This work was supported by the National Institute of Health Research School for Primary Care Research (NIHR SPCR) FR11 and Capacity Award 6 programmes [UCL Award 6, 322]. This article presents independent research funded by the National Institute for Health Research (NIHR). The views expressed are those of the author(s) and not necessarily those of the NHS, the NIHR or the Department of Health.

\section{REFERENCES}


Alzheimer's Society. (2013). Carer Support. Retrieved from https://www.alzheimers.org.uk/info/20091/what_we_think/86/carer_support; http://www.webcitation.org/6xE0DR7ht

Braun, V., \& Clarke, V. (2006). Using thematic analysis in psychology. Qualitative research in psychology, 3(2), 77-101.

Briggle, A. (2008). Real friends: How the Internet can foster friendship. Ethics and Information Technology, 10(1), 71-79.

Broady, Saich, \& Hinton. (2018). Caring for a family member or friend with dementia at the end of life: A scoping review and implications for palliative care practice. Palliative Medicine. Doi: $10.1177 / 0269216317748844$

Brown, M. A., Sampson, E. L., Jones, L. \& Barron, A. M. 2013. Prognostic indicators of 6month mortality in elderly people with advanced dementia: a systematic review. Palliative Medicine, 27, 389-400.

Cheng, S.-T., Lam, L. C., Kwok, T., Ng, N. S., \& Fung, A. W. (2013). The social networks of Hong Kong Chinese family caregivers of Alzheimer's disease: Correlates with positive gains and burden. The Gerontologist, 53(6), 998-1008.

Cocking, D., \& Kennett, J. (1998). Friendship and the self. Ethics, 108(3), 502-527.

Cuijpers, P. (2005). Depressive disorders in caregivers of dementia patients: a systematic review. Aging \& mental health, 9(4), 325-330.

Daly, L., McCarron, M., Higgins, A., \& McCallion, P. (2013). 'Sustaining Place'-a grounded theory of how informal carers of people with dementia manage alterations to relationships within their social worlds. Journal of Clinical Nursing, 22(3-4), 501-512.

Dam, A. E., Boots, L. M., van Boxtel, M. P., Verhey, F. R., \& de Vugt, M. E. (2017). A mismatch between supply and demand of social support in dementia care: a qualitative study on the perspectives of spousal caregivers and their social network members. International Psychogeriatrics, 1-12.

Davies, N., Maio, L., Rait, G., \& Iliffe, S. (2014). Quality end-of-life care for dementia: What have family carers told us so far? A narrative synthesis. Palliative Medicine, 28(7), 919-930.

Davies, N., Rait, G., Maio, L., \& Iliffe, S. (2017). Family caregivers' conceptualisation of quality end-of-life care for people with dementia: A qualitative study. Palliative Medicine, 31(8), 726-733.

Davis, L. L., Gilliss, C. L., Deshefy-Longhi, T., Chestnutt, D. H., \& Molloy, M. (2011). The nature and scope of stressful spousal caregiving relationships. Journal of Family Nursing, 17(2), 224-240.

Duggleby, W., Williams, A., Wright, K., \& Bollinger, S. (2009). Renewing everyday hope: the hope experience of family caregivers of persons with dementia. Issues in mental health nursing, 30(8), 514-521.

Glaser, B., \& Strauss, A. (1967). The discovery of Grounded Theory. Chicago: Aldine.

Griffith, K., McGuire, D.B., \& Russo, M. (2010). Meeting survivors' unmet needs: An integrated framework for survivor and palliative care. Seminars in Oncology Nursing, 26(4), 231-242.

Heo, J., Chun, S., Lee, S., Lee, K. H., \& Kim, J. (2015). Internet Use and Well-Being in Older Adults. Cyberpsychology, Behavior, and Social Networking, 18(5), 268-272.

Hopwood, J., Rait, G., Walters, K., Iliffe, S., Ross, J., \& Davies, N. (2018). A systematic review of digital interventions aimed at supporting family carers of people with dementia. Journal of medical Internet research, 20 (6).

Keating, N., \& Eales, J. (2017). Social consequences of family care of adults: a scoping review. International Journal of Care and Caring, 1(2), 153-173.

Kharicha, K., Manthorpe, J., Iliffe, S., Davies, N., \& Walters, K. (2018). Strategies employed by older people to manage loneliness: Systematic review of qualitative studies and model development. International Psychogeriaatrics. DOI: 10.1111/hsc.12438. 
Kimble C, Greniera C, Goglio-Primard K. (2010) Innovation and knowledge sharing across professional boundaries: Political interplay between boundary objects and brokers International Journal of Information Management;30:437-444.

Kneebone, I. I., \& Martin, P. R. (2003). Coping and caregivers of people with dementia. British journal of health psychology, 8(1), 1-17.

Lamont, M., \& Molnár, V. (2002). The study of boundaries in the social sciences. Annual review of sociology, 28(1), 167-195.

Lewis, L. F. (2015). Caregiving for a Loved One With Dementia at the End of Life:An Emergent Theory of Rediscovering. American Journal of Alzheimer's Disease \& Other Dementias ${ }^{\circledR}, 30(5)$, 488-496.

Lewis, F., Karlsberg Schaffer, S., Sussex, J., O'Neill, P. and Cockcroft, L. (2014) The Trajectory of Dementia in the UK - Making a Difference. Office of Health Economics.

Retrieved from: https://www.ohe.org/publications/trajectory-dementia-uk-making-difference\# Mays, N., \& Pope, C. (2000). Assessing quality in qualitative research. British Medical Journal, 320(7226), 50-52. doi:10.1136/bmj.320.7226.50

Nay, R., Bauer, M., Fetherstonhaugh, D., Moyle, W., Tarzia, L., \& McAuliffe, L. (2015). Social participation and family carers of people living with dementia in Australia. Health and Social Care in the Community, 23(5), 550-558.

O'Connor, D. L. (2007). Self-identifying as a caregiver: Exploring the positioning process. Journal of Aging Studies, 21(2), 165-174.

Office for national Statistics. (2017). Statistical bulletin: Internet users in the UK: 2017. Retrieved from London:

https://www.ons.gov.uk/businessindustryandtrade/itandinternetindustry/bulletins/inter netusers/2017\#recent-internet-use-for-those-aged-65-and-over-is-catching-up-withyounger-age-groups

Ory, M. G., Hoffman, R. R., III, Yee, J. L., Tennstedt, S., \& Schulz, R. (1999). Prevalence and impact of caregiving: a detailed comparison between dementia and nondementia caregivers. Gerontologist, 39(2), 177-185.

Tilly, C. (1998). Durable Inequality. Berkeley: University of Califronia Press.

Zickuhr K, \& Madden M. (2012). Older adults and internet use: For the first time, half of adults age 65 and older are online. Retrieved from Washington 